\title{
Respiratory Distress Management with Pulmonary Recruitment in Preterm Newborns, Preliminary Report
}

\author{
Orozco-Gutiérrez Alberto ${ }^{1 *}$, Sánchez-Gómez Regina², Orozco-del-Pino Pedro ${ }^{3}$ and Nuñez-del-Prado-Alcoreza José ${ }^{4}$ \\ ${ }^{1}$ Head of the Neonatology Department, Professor of Pediatrics and Neonatology, Ángeles del Pedregal Hospital, Mexico \\ ${ }^{2}$ Facultad Mexicana de Medicina, la Salle University, México
} ${ }^{3}$ Department of Probability and Statistics, Mathematics Investigation Center (CIMAT), México ${ }^{4}$ Pediatrics and Neonatology Department at Angeles del Pedregal Hospital, México City

Submission: December 01, 2017; Published: January 08, 2018

*Corresponding author: Orozco-Gutierrez, Head of the Neonatology Department, Professor of Pediatrics and Neonatology, Ángeles del Pedregal Hospital, Mexico, Camino a Santa Teresa 1055-109.Heroes de Padierna, D.F. 10700, Mexico, Tel: +52-55-56528688;

Email: Alberto.orozcogutierrezalberto@gmail.com

\begin{abstract}
This work studies the employment of CPAP with mask, administered in 3 periods of 10 minutes each hour (pulmonary recruitment) for the management of neonatal respiratory difficulty in 22 premature infants between 29 and 34 weeks of gestational age. The average weight was $1663 \mathrm{~g}$ in the recruited children and $1724 \mathrm{~g}$ in the non-recruited children. There was no difference in weight, gestational age, prenatal steroids and severity of respiratory difficulty. One of eleven patients in the recruited group required mechanical ventilation and six of eleven patients in the non-recruited group. Surfactant was used in 3/11 of the recruited and 6/11 of the non-recruited children. The period of hospitalization was 22.9 days in the recruited group versus 25.7 in the non-recruited group. The relative risk shows that a recruited patient is 6 times less likely to be intubated.
\end{abstract}

\section{Introduction}

At birth, the amniotic fluid found in the alveoli must be reabsorbed to allow the exchange of gases. The other fundamental change during adaptation at birth is the vasodilation of the pulmonary vessels and the following transportation of oxygen to the entire organism [1]. In the mature and healthy lung, gas exchange depends on the diffusion gradient of the gases, the alveolar surface area and the thickness of the alveolar-capillary membrane. The re absorption of pulmonary liquid depends on the hydrostatic pressures generated by inhalation and on the sodium re absorption osmotic gradient, which causes the movement of fluids to the interstitial tissue [2]. In preterm babies, the sodium re absorption mechanisms are immature and the respiratory force is weaker, so the hydrostatic pressure is lower and can affect the re absorption of the liquid [2]. In a structurally immature lung that is partially occupied by liquid, with increased alveolar wall thickness due to immaturity, the diffusion of gas is lower. These children often have consumption of surfactant, which causes alveolar collapse and ventilatory problems [3-5]. Ventilating premature infants with continuous positive pressure prevents the collapse of the airway at the end of exhalation and helps to increase the re absorption of liquid in the airway. This improves ventilation, oxygenation, increases pulmonary volume and elasticity, which increases the pressure at the end of exhalation and decreases the resistance of the airways. It also maintains the surfactant, alveolar collapse and the synthesis of pro inflammatory mediators $[4,5]$. In studies with immature animals, using positive end-expiratory pressure (PEEP) of $5 \mathrm{~cm}$ of $\mathrm{H} 2 \mathrm{O}$ during stabilization at birth improves uniform lung aeration and the elimination of pulmonary fluid thus increasing residual functional capacity, oxygenation, lung compliance and decreasing lung damage [6]. Continuous positive pressure has been used to prevent and treat respiratory distress syndrome (RDS) and reduces bronchopulmonary dysplasia and mortality [7]. A randomized controlled study application of 10 seconds of continuous ventilation continuous positive nasal airway pressure (CPAP) versus bag-mask ventilation in premature babies showed reduction in the need for intubation in the first 72 hours, lower duration of respiratory assistance, less use of surfactant and decreased risk of bronchopulmonary dysplasia [8]. The use of 
PEEP and/CPAP in the delivery room (15 minutes after birth) reduces the number of children requiring intubation and stabilizes premature babies with respiratory difficulties [3,9]. Hany Aly found that the early administration of nasal CPAP reduces the need for intubation, mechanical ventilation and the use of surfactant [10]. Mulrooney reports that the use of CPAP between 5 and $8 \mathrm{~cm}$. H2O in sheep increases the secretion of phosphatidylcholine between 2 and 6 hours of life and helps with the onset of spontaneous ventilation [5]. A study similar to ours with alveolar recruitment, using continuous PEEP and increasing the pressure $0.2 \mathrm{~cm} \mathrm{H} 2 \mathrm{O}$ every 5 minutes, until reaching $(\mathrm{FiO} 2)=0.25$, showed a lesser need for FiO2, lower number of doses of surfactant and less dependency on supplementary oxygen [11]. This work aims to determine if the intermittent application of continuous distending pressure in premature infants with moderate respiratory difficulty, at the onset of respiratory difficulty, reduces the need for mechanical ventilation, use of surfactant and the duration of hospitalization.

\section{Patients and Methods}

We observed 22 premature infants under 34 weeks who had moderate respiratory difficulty and were rated as having a ACORN respiratory score greater than 4 in the first hour of life [12].

The patients were treated diferently according to the criteria of the attending physician:

Group 1 (none recruited): received treatment according to respiratory distress severity, including oxygen, CPAP, surfactant and mechanical ventilation.

Group 2 (recruited group): received CPAP at $5 \mathrm{~cm} \mathrm{H} 20$ pressure with continuous flow mask and bag for 10 minutes every hour for three hours or until the respiratory difficulty disappeared, and supplementary oxygen to maintain transcutaneous saturation between 90 and $94 \%$.

The evolution was evaluated observing the need of ventilation support, administration of surfactant, oxygen requirements and length of hospital stay.

Results

Table 1: Population characteristics by group.

\begin{tabular}{|c|c|c|}
\hline & RECRUITED & NON RECRUITED \\
\hline WEIGHT $(\mathrm{kg})$ & $1.663(1.060-2.270)$ & $1.724(1.140-2.260)$ \\
\hline SEX (MALE) & $5 / 11(45 \%)$ & $6 / 11(54 \%)$ \\
\hline GESTATIONAL AGE & $32.7(29-34)$ & $32.6(31.6-34.4)$ \\
\hline PRENATAL STEROIDS & $9 / 11(82 \%)$ & $8 / 11(73 \%)$ \\
\hline $\begin{array}{c}\text { RESPIRATORY DISTRESS } \\
\text { SEVERITY (ACORN } \\
\text { respiratory Score) }\end{array}$ & $4.81 \mathrm{SD}+/-(0.72)$ & $4.63 \mathrm{SD}+/-(0.62)$ \\
\hline
\end{tabular}

Weight, gestational age and sex were similar in both groups, as shown in Table 1. The respiratory evolution in both groups is shown in. All patients survived without extra-pulmonary complications. Mechanical ventilation was more frequent in the non-recruited group (6/11) compared to the recruited group (1/11). In Figure 1, the likelihood confidence interval shows a diminished tendency of needing mechanical ventilation in the recruited group.

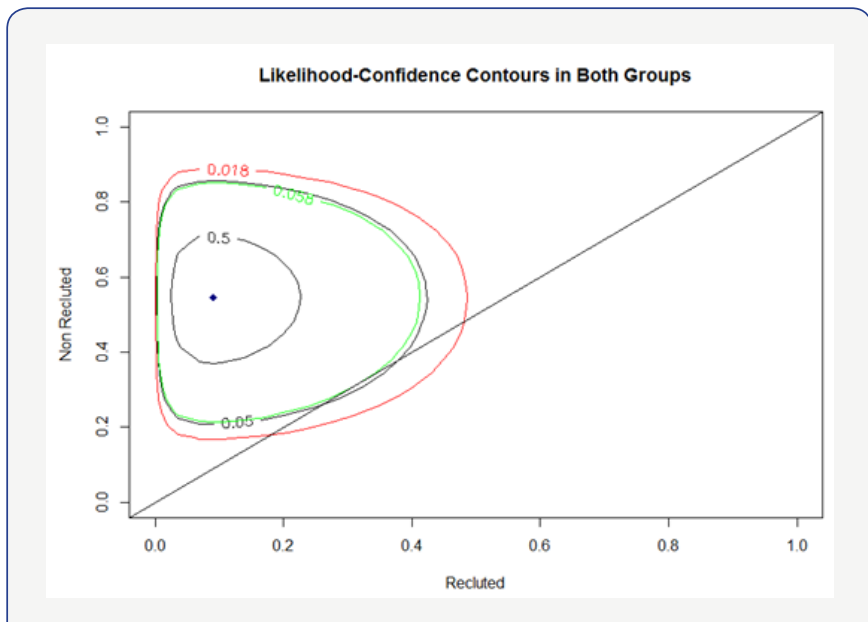

Figure 1: Mechanical ventilation need compared tendency.

For the analysis in this study, we employed the likelihood function. This is a function of the parameters of a statistical model that allows inferences to be made about the Characteristics of a Population of interest from a set of observations.

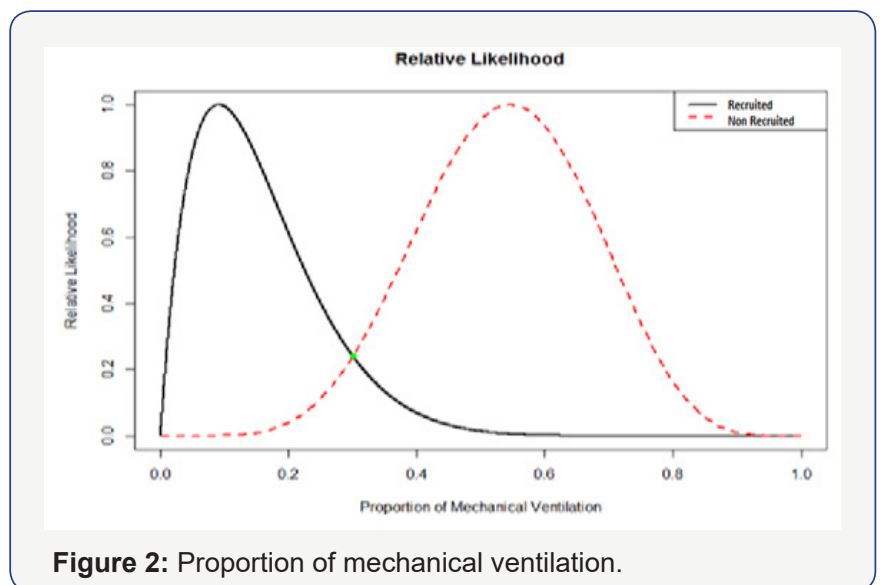

The Figure 2 represents the relative likelihood of each parameter in graph form; we observed that they intersect at 0.3 with plausibility of $24 \%$ of being the proportion that both groups share. This strongly suggests that the low proportion of children intubated corresponds with the fact that recruitment was present.

This data supports the hypothesis that recruitment in larger groups will have the same results: a lesser need for mechanical ventilation in the presence of alveolar recruitment.

Another method of evaluating the proposal is by obtaining the odds which is defined as the proportion of those being investigated who required mechanical ventilation divided by that of the control group. In this case, the number of intubated children receiving treatment is $(1 / 11)$, and not receiving treatment $(6 / 11)$. This 
means that it is more likely that a child who receives treatment does not need mechanical ventilation.

If we obtain a result close to 1 , this means that both treatments are equally effective. In this case, the odds ratio is less than 1 , verifying that the treatment avoids mechanical ventilation.

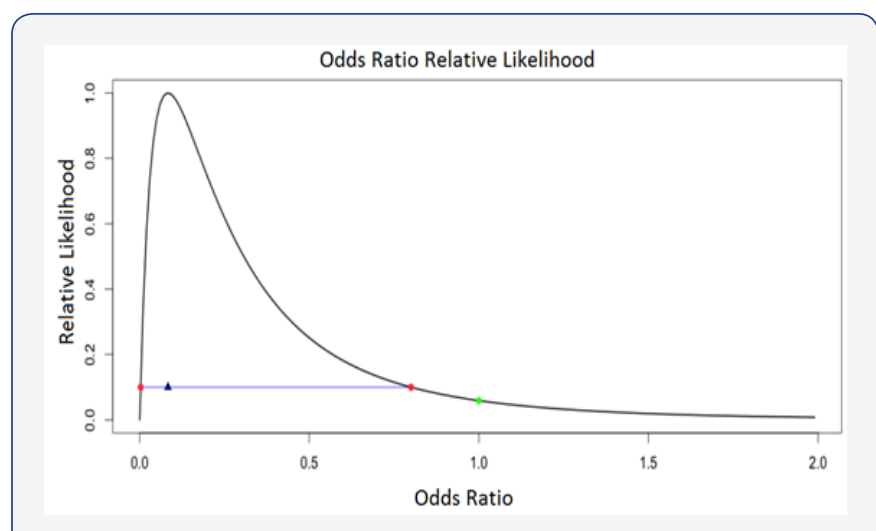

Figure 3: Odds ratio Relative likelihood.

In Figure 3, it can be seen that the most credible value for the relationship of probabilities is 0.083 , with a $10 \%$ likelihood interval that equals $(0.0026,0.8)$ which does not reach 1 . This means that the values outside of this interval are at least 10 times less credible than those within the interval.

The ratio of relative probability of the likelihood is shown in Figure 3. table. We can see that the most credible value for the odds ratio is 0.083 , with a $10 \%$ likelihood interval that equals $(0.0026$ to 0.8$)$ which does not contain 1 . This means that the values outside of this interval are 10 times less credible than those within it and that the value of 1 has a plausibility of 5.9\%, telling us that it is highly improbable that they are equally efficient and also that the treatment is far superior at avoiding intubation. As in previous cases, the likelihood function of the relative risk is shown. Here we can see that the most plausible value of the relative risk is 0.16 with a $10 \%$ likelihood interval that $(0.0065$, 0.8595 ) not containing 1 , which means that the values outside of this interval are 10 times less credible that those within it and that the values for those which the relative risk is greater than 1 have a probability of less than $6 \%$.

\section{Discussion}

This work describes the treatment of mild and moderate respiratory distress syndrome in 22 premature infant of less than 34 weeks. The patients were divided into two groups of 11 children with similar characteristics in each group, with one group using an alveolar recruitment maneuver and the other following habitual management with supplementary oxygen. Eight patients in the recruited group and four patients in the control group were treated with CPAP. Three recruited patients and no patients in the control group received surfactant with the Insure method (intubationsurfactant-extubation). Only one recruited patient required mechanical ventilation in comparison with six in the control group. The days of hospitalization were similar in both groups. The recruited patients in this protocol received Peep of $5 \mathrm{~cm}$ of $\mathrm{H} 2 \mathrm{O}$ and did not present complications associated with the recruitment. This must be evaluated with a greater number of patients. The patients evaluated in this study did not have extra-pulmonary complications which could have interfered with the results. The most promising result is the reduction in the need for mechanical ventilation in recruited patients, which reduces the potential risk of complications and associated costs. Previous studies have demonstrated the use of LRM (lung recruitment maneuver) with progressive increases in Peep in ventilated children reduces the FiO2 requirements during the first 12 hours of life and reduces supplementary oxygen dependency. The difference in our study is that recruitment was only carried out for 10 minutes each hour for 3 episodes [11]. The evidence in previous studies in animals and humans has demonstrated that the use of CPAP significantly diminishes barotrauma and mechanical ventilation in premature infants with respiratory difficulty. This is the basis for using CPAP intermittently to reduce the need for mechanical ventilation even further. This strategy reduces the need for mechanical ventilation and the use of surfactant. However, the number of days of CPAP increased and it does not affect hospitalization time. The size of the sample was small, which is why inferential statistics was used to obtain valid results in larger scale projections. However, larger studies must be carried out in order to validate the results.

\section{Conclusion}

It is demonstrated that the use of intermittent CPAP as a recruitment maneuver in newborns with mild to moderate respiratory difficulty reduces mechanical ventilation and the application of surfactant without increasing complications. This can open a new line of investigation in order to determine if it can be recommended as a safe and easy application strategy in larger groups.

\section{Financing}

This investigation did not receive any specific grant from any organism and was completely financed by the by the investigators.

\section{Conflict of Interest Declaration}

The authors declare that there are no conflicts of interest. The authorization of the research and ethics committees and the informed consent of the parents were obtained.

\section{References}

1. Wyckoff MH, Aziz K, Escobedo MB, Kapadia VS, Kattwinkel J, et al (2005) Neonatal Resuscitation: 2015 American Heart Association Guidelines Update for Cardiopulmonary Resuscitation and Emergency Cardiovascular Care. Circulation 132(18): S543-S560.

2. ML ST, Wallace MJ, Kitchen MJ, Lewis RA, Fouras A (2009) Enhances odds pressure positive and development of a functional residual capacity in ventilated preterm rabbits from birth. J Appl Physiol 106(5): 1487-1493.

3. Megan EP, Stuart B, Hooper, Peter AD, Naomi M (2004) Positive End 
Expiratory Pressure During Resuscitation of Premature Lambs Rapidly Improves Blood Gases without adversely Affecting Blood Pressure. Pediatr Res 56(2): 198- 204.

4. Subramaniam P, Ho JJ, Davis PG (2016) Prophylactic nasal continuous positive airway pressure for preventing morbidity and mortality in very preterm infants. Cochrane Database Syst Rev 14(6).

5. Mulrooney N, Champion Z, Moss TJ, Nitsos I, Ikegami M(2005) Surfactant and physiologic responses of preterm lambs to continuous positive airway pressure. Am J Respir Crit Care Med 171(5): 488-493.

6. Te Pas AB, Siew M, Wallae MJ, Fouras A, Lewis RA, et al. (2009) Establishing Residual Functional Capacity at Birth: The Effect of Sustained Inflation and Positive End-Expiratory Pressure in to Preterm Rabbit Model. Pediatr Res 65(5): 537-541.

7. Ho JJ, subramaniam P, Henderson-Smart DJ, Davis PG (2002) Continuous Distending Pressure for respiratory distress in preterm infants. Cochrane Database Syst Rev Issue.

8. Arjan BP, Frans J, Walther (2007) A randomized, controlled trial of delivery-room respiratory management in very preterm infants. Pediatric 120(2).

9. Stacie B, Neil NF, Wade R, Yvonne V (2005) A comparison of three neonatal resuscitation devices. Resuscitation 67(1) 113-118.

10. Hany AMD, MD AN, Massaro, Kantilal P, Ayman El-Mohande (2005) Is It Safer to Intubate Premature Infants in the Delivery Room? Pediatrics 115(6) 1660-1665.

11. R Wu, S-B Li, ZF Thian, Zheng GF, Zhao YX (2014) Lung Recruitment maneuver during proportional assist ventilation of preterm infants with acute respiratory distress syndrome. J Perinatol 34(7), 524-527

12. Alfonso S, Judith L, Emily L, Debra O, Horacio O(2009) Acorn: Acute Care of At-Risk Newborns; ACoRN Group, p. 32.

\section{Your next submission with Juniper Publishers will reach you the below assets}

- Quality Editorial service

- Swift Peer Review

- Reprints availability

- E-prints Service

- Manuscript Podcast for convenient understanding

- Global attainment for your research

- Manuscript accessibility in different formats

( Pdf, E-pub, Full Text, Audio)

- Unceasing customer service

Track the below URL for one-step submission https://juniperpublishers.com/online-submission.php 